\title{
Situação de Estudo como artefato para a qualificação metodológica na formação inicial de professores de química: um caso específico das Rodas de Conversa
}

\section{Study Situation as an artifact for a methodological qualification in the initial formation of chemistry teachers: a specific case of Circles of Conversations}

\author{
Everton Bedin* \\ José Claudio Del Pino**
}

\begin{abstract}
RESUMO
Este artigo tem o intuito de apresentar a metodologia de Situação de Estudo como um mecanismo de organização curricular no ensino de ciências à luz da qualificação inicial de professores no viés das Rodas de Conversa, ponderando a fala destes sujeitos como intensificadora desta ação. Os dados da pesquisa foram obtidos por meio da técnica da observação durante as discussões nas Rodas de Conversa e transcritos em um diário de bordo; analisados, interpretados e debatidos por meio de referencial teórico. No término, averiguou-se que os sujeitos da pesquisa valorizam a aprendizagem científica do aluno por meio do trabalho docente via Situação de Estudo, compreendendo suas necessidades diante do contexto atual e sua abrangência sobre a importância de práticas pedagógicas que melhor norteiam os processos de ensino e aprendizagem.
\end{abstract}

Palavras-chave: Situação de Estudo. Rodas de Conversa. Formação inicial de professores. Metodologia docente.

* Universidade Luterana do Brasil. Unidade Universitária de Canoas. E-mail: bedin.everton@ gmail.com. ORCID: https://orcid.org/0000-0002-5636-0908

** Universidade Federal do Rio Grande do Sul. Programa de Pós-Graduação em Ciências: Química da Vida e Saúde. E-mail: delpinojc@yahoo.com.br. ORCID: https://orcid.org/0000-00028321-9774 


\begin{abstract}
This article intends to present the methodology of Situation of Study as a mechanism of curricular organization in the teaching of science in the light of the initial qualification of teachers in the bias of the Circles of Conversation, pondering the speech like intensifier of this action. The data of the research were obtained by means of the observation technique during the discussions in the Circles of Conversation and transcribed in a logbook; analyzed, interpreted and debated by means of theoretical reference. In conclusion, it was noticed that teachers value the scientific learning of the student through the teaching work via Study Situation, understanding the general aspects of the process and your importance of the pedagogical practices that best guide the teaching and learning processes.
\end{abstract}

Keywords: Situation of study. Circles of Conversations. Initial teacher formation. Teaching Methodology.

\title{
Primeiros passos: relevando a necessidade de aperfeiçoar as metodologias docentes
}

A formação inicial ou continuada de professores é pauta para debate em cursos de extensão, palestras e, até mesmo, em disciplinas específicas na graduação. Apesar de hoje ser muito trabalhada e explorada, desde muito cedo este tema vem sendo considerado como artefato de qualificação no ensino, pois, de acordo com Rodríguez Diéguez (apud MARCELO, 1999), na década de 80 se considerava esta formação como "um ensino profissionalizante para o ensino", ou seja, a formação inicial de professores devia instruí-los a pensar, planejar e desenvolver ações que valorizassem o aluno no contexto de sala de aula.

Nesta vertente, autores como Medina e Dominguez, já na década de 90, passaram a considerar que a formação de professores deveria prepará-los de forma crítica e reflexiva, a fim de desenvolver um "estilo de ensino que promova uma aprendizagem significativa nos alunos e consiga um pensamento-ação inovador, trabalhando em equipe com os colegas para desenvolver um projeto educativo comum (apud MARCELO, 1999, p. 87). Em 1992, o pesquisador português António Nóvoa (1992, p. 25), apresentou em um de seus estudos o aspecto da autonomia do professor, considerando que a formação "deve estimular uma perspectiva crítico-reflexiva, fornecendo aos professores os meios de um pensamento autônomo e que facilite as dinâmicas de autoformação participada".

Os processos envolvendo a formação de professores passaram a evoluir no sentido de possibilitar a estes formação continuada e conjunta, estabelecendo 
a formação e os estudos de aperfeiçoamento em áreas de conhecimento. Nesta questão, o conceito de formação de professores adotado por Marcelo (1999) corresponde:

[...]a área de conhecimentos, investigação e de propostas teóricas e práticas que, no âmbito da Didática e da Organização Escolar, estuda os professores através dos quais os professores - em formação ou em exercício -se implicam individualmente ou em uma equipe, em experiências de aprendizagem através das quais adquirem ou melhoram os seus conhecimento, competências e disposições, e que lhes permite intervir profissionalmente no desenvolvimento do seu ensino, do currículo e da escola, com o objetivo de melhorar a qualidade da educação que os alunos recebem (MARCELO, 1999, p. 26).

Ao serem interpretadas as palavras de Marcelo, pode-se perceber que este remete à formação inicial e/ou continuada de professores para além da ação conjunta, configurando-a como um mecanismo de experiência de aprendizagem em constante processo de construção e reconstrução de saberes; logo, encontra-se o desenvolvimento do profissional da educação em relação à aquisição de competências e habilidades, quanto à qualificação dos processos de ensino e aprendizagem.

Neste desenho, percebe-se que existe uma valorização crescente na formação do professor desde a década de 80 , quando o mesmo era requisitado a pensar práticas para qualificar o ensino na educação básica. Hoje, a formação consagra-se para além do ensino, buscando a figura do professor como membro significativo dessa qualificação. Isto é, quando se cogita a pesquisa como meio de formação de professores possibilita-se a estes a reflexão e o questionamento sobre o próprio trabalho, o que os faz, em uma ação continua na prática, analisar as colocações que os alunos apresentam para, de forma significativa, traçar um perfil eficiente de intervenções didáticas para propor a realização de um planejamento de interpretação e proliferação de saberes.

Assim, de acordo com Santos (2001, p. 16), o professor ajuíza ações para além dos conteúdos mínimos, pois este desempenha um papel de pesquisador, "identificando problemas de ensino, construindo propostas de solução com base na literatura e em sua própria experiência, colocando em ação as alternativas planejadas, observando e analisando os resultados obtidos", a fim de corrigir aqueles que se mostraram pouco satisfatórios.

Apesar dos descritos acima, Azanha (2004) afirma que a escola de hoje se tornou, mesmo com a frequente luta pela formação docente de qualidade, um 
anacronismo da escola do passado. Para ele, "a escola básica de hoje não é [...] um retrocesso com relação à escola de ontem. É uma outra escola, principalmente por ser altamente expandida, e suas alegadas deficiências precisam ser enfrentadas por um esforço permanente de investigação e busca". (AZANHA, 2004, p. 373). Isto pode decorrer da concepção de que muitos profissionais ainda acreditam que "o mais importante é o conteúdo a ser transmitido, aparecendo o educador como simples provedor dos conhecimentos e o educando como simples receptáculo desses conteúdos”. (PARO, 2010, p. 21).

Todavia, compreende-se que o professor precisa estar além de seu tempo didático, no sentido de não ser um transmissor, mas um facilitador de informações que, ao serem adquiridas e diagnosticadas pelo estudante, em meio à contextualização, transformam-se em conhecimento. Da mesma forma, a escola, berço dessas ações e fixada ao contexto sociocultural do educando, deve ser entendida como um espaço institucional "no qual as relações pedagógicas possíveis não podem ser modeladas a partir apenas de métodos e procedimentos de alguém que ensina e de habilidades, competências e qualidades psicológicas de alguém que aprende". (AZANHA, 2004, p. 372).

A escola contemporânea é, pois, uma novidade social e cultural. Nesse novo espaço institucional, o desempenho do professor não mais pode ser pensado como uma simples questão de formação teórica de alguém que ensina, como também o desempenho do aluno não mais pode ser considerado como uma simples questão de motivação e de esforços individuais. A escola de hoje é uma ruptura com a escola do passado, sempre inspirada numa visão preceptorial da relação pedagógica. (AZANHA, 2004, p. 372).

Diante dos fatos, e considerando o proposto até o momento, este artigo tem o intuito de apresentar a metodologia de Situação de Estudo como um mecanismo de organização curricular no ensino de ciências à luz da qualificação inicial de professores no viés das Rodas de Conversa, ponderando a fala desses sujeitos como intensificadora dessa ação. Essa metodologia enquadra-se na qualificação didática de professores em formação inicial para a contemporaneidade, pois se acredita ser necessário aperfeiçoar e redimensionar as afinidades e métodos escolares, urgentemente.

Portanto, este trabalho se justifica na relação da Situação de Estudo às Diretrizes para a Formação Inicial de Professores da Educação Básica, em Cursos de Nível Superior, quando estas expõem que: 
As mudanças propostas para a Educação Básica no Brasil trazem enormes desafios à formação de professores. No mundo contemporâneo, o papel do professor está sendo questionado e redefinido de diversas maneiras. Para isso, concorrem as novas concepções sobre a educação, as revisões e atualizações nas teorias de desenvolvimento e aprendizagem, o impacto da tecnologia da informação e das comunicações sobre os processos de ensino e de aprendizagem, suas metodologias, técnicas e materiais de apoio. Tudo isso delineia um cenário educacional com exigências para cujo atendimento os professores não foram, nem estão sendo preparados. (BRASIL, 2000, p. 5).

\section{Metodologia da pesquisa}

Pensando em intensificar o objetivo deste trabalho, o qual deriva da ideia de apresentar a metodologia de Situação de Estudo como um mecanismo de organização do trabalho docente no ensino de ciências à luz da fala de professores em formação inicial, adotou-se o método hermenêutico apoiado em uma visão fenomenológica desta ação. Ou seja, a fenomenologia da hermenêutica descreve um fenômeno ou um fato a partir de uma visão pessoal ou de uma experiência do mundo sem explicação ou interpretação; delineia o mundo vivido/experiência a partir do que é observado. (TRIVIÑOS, 2013).

Em colaboração, Pimenta (2000) afirma que a pesquisa fenomenológica parte da compreensão do viver; uma concepção que ignora definições e conceitos para conseguir atingir a ideia de compreensão que orienta a atenção para aquilo que se vai investigar; logo, novas compreensões emergem a cada momento, pois estas derivam de novas interpretação que resultam de novas características do fenômeno. Esta técnica é muito utilizada na educação, pois, na maioria das vezes, os dados são oriundos de sujeitos; o grupo focal ou público-alvo são pessoas em formação, o que requer a técnica hermenêutica, já que estes se encontram em constante formação; novas interpretações e compreensões surgem na medida em que a identidade do sujeito vai sendo formada.

Neste sentido, Abbagnano (1998) afirma que hermenêutica é qualquer técnica de interpretação, sendo um procedimento de pesquisa comum na educação por utilizar como alternativa a interpretação do pesquisador para a produção do conhecimento. Contudo, essa abordagem fenomenológica da hermenêutica não é sustentada por um único conceito, pois é estabelecida de linguagens e, apenas, interpretada. Assim, o pesquisador passa a ser o intérprete da realidade que, segundo Trevisan, Tomazetti e Rossatto (2010, p. 372), tem o objetivo de 
"tornar compreensível o objeto da investigação, não como ele se apresenta de imediato, mas por meios interpretativos dentro do seu contexto histórico de acontecimentos".

Portanto, o intuito de a pesquisa estar centrada na proposta fenomenológica hermenêutica é que essa não apenas descreve as vozes, as falas e a linguagens dos sujeitos que compõem a amostra, mas apresenta, por meio de uma interpretação minuciosa do pesquisador - sujeito que fez parte do desenvolvimento - o que este meio esclarece rumo à transformação desta prática. Nesta perspectiva, entende-se que a pesquisa hermenêutica proporciona aos sujeitos, além do pesquisador, um espaço/tempo de escuta e reflexão na/sobre a prática, derivando-se em um processo de construção de conhecimentos e de transformação do contexto do qual faz parte, a fim de que se possa compreender como a metodologia de SE - Situações de Estudo pode organizar o trabalho docente.

Ainda, é sagaz destacar que os sujeitos que fazem parte desta pesquisa são dez licenciandos do curso de Química Licenciatura Plena de uma universidade privada de Canoas, município metropolitano de Porto Alegre, capital do Estado do Rio Grande do Sul. Estes sujeitos, professores em formação inicial (PFI), expressaram concordância na participação da pesquisa e divulgação dos resultados, desde que suas identidades fossem preservadas; logo, para apresentar de forma extensiva e fundamentar com teóricos os resultados abaixo, obtidos através da observação e transcritos em um diário de bordo durante as Rodas de Conversa pelo pesquisador, os PFI estão representados pelas sílabas iniciais de seus nomes.

\section{A Situação de Estudo como proposta de organização de trabalho}

A organização do trabalho docente e a aplicação das metodologias de ensino, com vistas a contextualização e aprimoramento dos processos de ensino e aprendizagem, não dependem exclusivamente do professor, mas da realidade que o cerca e do contexto dos alunos. Assim, entende-se que o currículo da educação básica não pode determinar os conteúdos mínimos necessários para que o aluno, ao término do terceiro ano do ensino médio, consiga adentrar no ensino superior, devendo incorporar ações de formação integral para que consiga desenvolver senso crítico, interpretar fenômenos de sua vivência e resolver problemas de seu cotidiano.

Nesta perspectiva, é necessário que os professores da rede pública de ensino apresentem competências e habilidades quanto às diferentes metodologias de 
ensino para despertar no educando o interesse pelo conhecimento, principalmente quanto às diferentes maneiras de construir saberes na relação com o outro e consigo mesmo. Esse processo é importante para que o professor contemple, diante de sua metodologia, as reais necessidades que o educando contemporâneo apresenta e ultrapasse os limites do treinamento puramente técnico para, efetivamente, alcançar a formação do homem como um ser histórico, inscrito na dialética da ação-reflexão-ação. (MITRE et al., 2008).

Neste sentido, durante um curso de extensão filantrópico, denominado Rodas de Conversa, para professores em formação inicial, em uma universidade privada da região metropolitana de Porto Alegre/RS apresentou-se a metodologia de Situação de Estudo, pois esta ancora-se na pedagogia crítica, a qual parte de uma maledicência sobre o ensino tradicional, propondo-se usar situação-problema para estimular à aquisição de saberes, conhecimentos e habilidades. (CYRINO; TORALLES-PEREIRA, 2004).

Essa proposta metodológica apresentada aos sujeitos da pesquisa deriva de estudos aprofundados do Grupo Interdepartamental de Pesquisa sobre Educação, da Universidade Regional do Noroeste do Estado do RS (GIPEC - UNIJUÍ), o qual preconiza uma nova forma, concepção e organização curricular para a educação básica, fundamentada em sucessivas Situações de Estudo (SE) (MALDANER; ZANON, 2001). Assim, trabalhar com SE como proposta de organização do trabalho docente é uma forma de inserir a contextualização e a interdisciplinaridade na prática pedagógica, priorizando essas abordagens ao selecionar uma temática abrangente, a qual vincula-se à seleção e organização dos conteúdos com perspectiva às propostas de ensino inseridas nas Diretrizes Curriculares Nacionais. (BRASIL, 2000).

Com o desenvolvimento da prática docente por meio da SE, a qual traz uma relação com o contexto do aluno - uma situação vivenciada -, aprimorando à articulação entre os saberes científicos com a vivência deste, pode-se permitir a evolução da apropriação dos conceitos e a ressignificação dos saberes num processo interativo; a capacidade de o aluno reconstruir a situação vivencial em forma conceitual passa a "constituir a mente dos aprendentes com novas formas de raciocínio, de abstração e de representação de mundo". (MALDANER, 2007b, p.10).

Maldaner e Zanon (2001, p. 49) definem a metodologia SE como "uma situação real (complexa, dinâmica, plural) e consequentemente rica, identificada nos contextos de vivência cotidiana dos alunos fora da escola, sobre o qual eles têm o que dizer e, no contexto da qual, eles sejam capazes de produzir novos saberes". Assim, ajuíza-se que quando o professor, partindo da conjetura de formador crítico e responsável pelo processo de ensinagem, em meio as competências e habilidades, trabalhar de maneira a constituir de forma concisa e 
qualificada a formação do sujeito por meio da problematização e da exploração da SE, consentirá na articulação com outros componentes curriculares, os quais favorecem a construção e reconstrução de novos saberes, expressando de forma autônoma e significativa suas conclusões.

Portanto, reconhecer o significado que o aluno tem na construção do saber pode partir da utilização da SE, pois, por ser pertinente e conexa ao contexto deste, este pode exprimir suas ideias, construir concepções e ressignificar seus saberes. Além disto, a SE pode, segundo Maldaner (2007a, p. 249)

[...] contemplar um número relativamente pequeno de conceitos centrais sendo estes sempre representativos da disciplina, compondo uma totalidade para cada disciplina e para o conjunto delas; [...] transacionar apenas significados iniciais para conceitos que aparecem pela primeira vez, podendo evoluir no desenvolvimento das SEs; [...] estimular a produção criativa e coletiva dos estudantes sobre o entendimento da situação estudada como uma totalidade; [...] permitir que sejam significados os conhecimentos científicos contemporâneos, uma decorrência natural quando se estuda uma situação concreta e as soluções tecnológicas atuais.

Diante do exposto, percebe-se que o trabalho docente pode estar organizado em sucessivas Situações de Estudo desde que o professor, munido de competências e habilidades, consiga desenvolver de forma significativa os conceitos que objetivou durante a escolha do tema, pois o estudante precisa ser instigado à pesquisa por meio da problematização e da curiosidade em resolver/estudar algo de sua vivência. Além disso, entende-se que a organização do trabalho por meio da SE acarreta na construção de atividades coletivas, a qual amplia possibilidades para minimizar questões relativas à fragmentação do conhecimento, a falta de articulação entre teoria e práticas e atividades interdisciplinares por meio da construção de novas práticas pedagógicas cooperativas.

\section{Das Rodas de Conversa às atividades desenvolvidas à luz da Situação de Estudo: a voz dos professores em formação inicial}

Rodas de Conversa é um projeto de extensão, de forma filantrópica, que visa à qualificação dos professores em formação inicial de química de uma universidade da região metropolitana da capital do Estado do Rio Grande 
do Sul. Este projeto, que ocorre desde o início do vigente ano em uma das salas de aula da universidade, tem como principal objetivo: proporcionar aos professores em formação inicial o desenvolvimento de metodologias diversificadas no entrelaçamento de concepções e perspectivas no viés de Rodas de Conversas à qualificação, maximização e proliferação dos processos de ensino e de aprendizagem na Educação Básica e na Educação Superior em um viés tecnológico-interdisciplinar, a fim de valorizar a construção de um cidadão crítico e responsável com o meio; assegurar formação de professores responsáveis com a educação básica, com práticas pedagógicas reflexivas, capazes de intervir de forma hábil e ativa no contexto socioeconômico do estudante.

Além do mais, para qualificar a formação inicial dos professores foi necessário realizar parceria com uma escola municipal, a qual abriu as portas para que, de formas significativa e qualificada, as metodologias que eram pensadas, discutidas, elaboradas e adaptadas à realidade local pudessem, por meio da ação dos professores em formação inicial, serem colocadas em práticas para averiguar, além do impacto destas na aprendizagem dos estudantes da rede municipal, a formação da identidade docente e o aprimoramento dos saberes docentes quanto às metodologias.

Uma das primeiras metodologias apresentadas aos PFI - sujeitos desta pesquisa - foi a Situação de Estudo. Para dialogar sobre esta e, ao mesmo tempo, apresentar a metodologia aos PFI, utilizou-se uma imagem que, em um viés didático e significativo da relação com as concepções educacionais de sondagem, contextualização e ressignificação de saberes dos alunos, encontrou-se em um artigo publicado pelos autores no vigente ano. A imagem, que teve como ponto de partida as atividades desenvolvidas pelo grupo nas Rodas de Conversa, apresenta-se na Figura 1.

De acordo com os autores, a imagem retrata uma adaptação das ideias de como desenvolver uma SE, derivada do Grupo Interdepartamental de Pesquisa sobre Educação em Ciências da Universidade Regional do Noroeste do Estado do Rio Grande do Sul (GIPEC/UNIJUÍ). Como princípio do trabalho, o professor deve definir o ano em que se trabalhará a SE, a temática que fará as conexões com o conteúdo e, talvez o mais importante, os conceitos básicos que serão, ao longo do desenvolvimento desta atividade, transformados em conhecimentos e saberes por meio da problematização.

Preparada a metodologia de desenvolvimento da SE, os autores (2017, p. 169) ajuízam a ideia de que o professor precisa "sondar as concepções prévias dos estudantes para, a partir de então, instigar e problematizar a realidade de cada um". Na sequência, compete ao professor o trabalho de ressignificar os conhecimentos do aluno e contextualizar estes a sua vivência, pois só assim ele conseguirá abstrair as principais ideias da atividade desenvolvida e delas 
FIGURA 1 - IMAGEM TRABALHADA COM OS PFI SOBRE O PLANEJAMENTO DE UMA SE

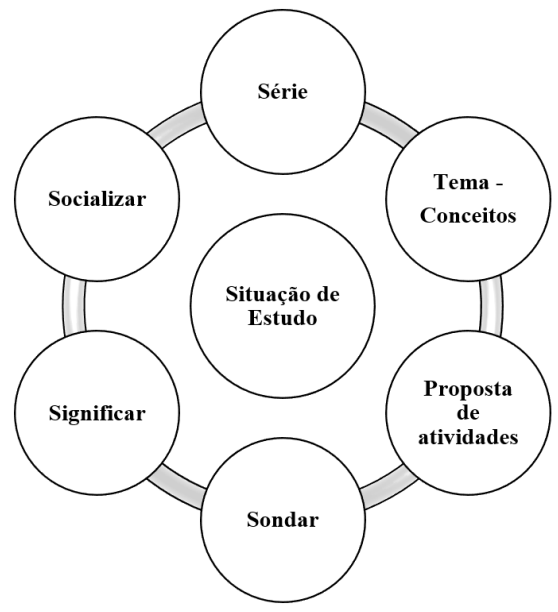

FONTE: https://periodicosonline.uems.br/index.php/interfaces/article/viewFile/1600/1357. Acesso em: 13 jun. 2017.

fazer uso significativo. Por fim, "é interessante que seja feita uma socialização das atividades desenvolvidas pelos estudantes a fim de que estes percebam a aprendizagem e a relação entre os saberes" (BEDIN; DEL PINO, 2017, p. 169).

Trabalhado essas ideias com os PFI durante três meses nas Rodas de Conversa, cogitou-os a produzirem, em duplas, um protótipo de SE a ser aplicado na educação básica, em especial no Ensino de Ciências, considerando os anos finais, desde o $6^{\circ}$ ano até o $9^{\circ}$ ano, da escola participante do projeto. Os protótipos desenvolvidos consideraram, além da realidade dos alunos por ano/ série, o conteúdo mínimo estruturado no currículo escolar e trabalhado pela professora titular.

Como critérios de curiosidade e qualificação do trabalho, apresenta-se a Figura 2 a seguir que retrata, além da temática selecionada pelos professores em formação inicial, o objetivo da SE com relação ao contexto dos alunos e o conteúdo mínimo curricular da grade de ciências da referida escola, parceira do projeto Rodas de Conversa. 


\section{FIGURA 2 - PROTÓTIPOS DE SE DESENVOLVIDOS PELOS PFI}

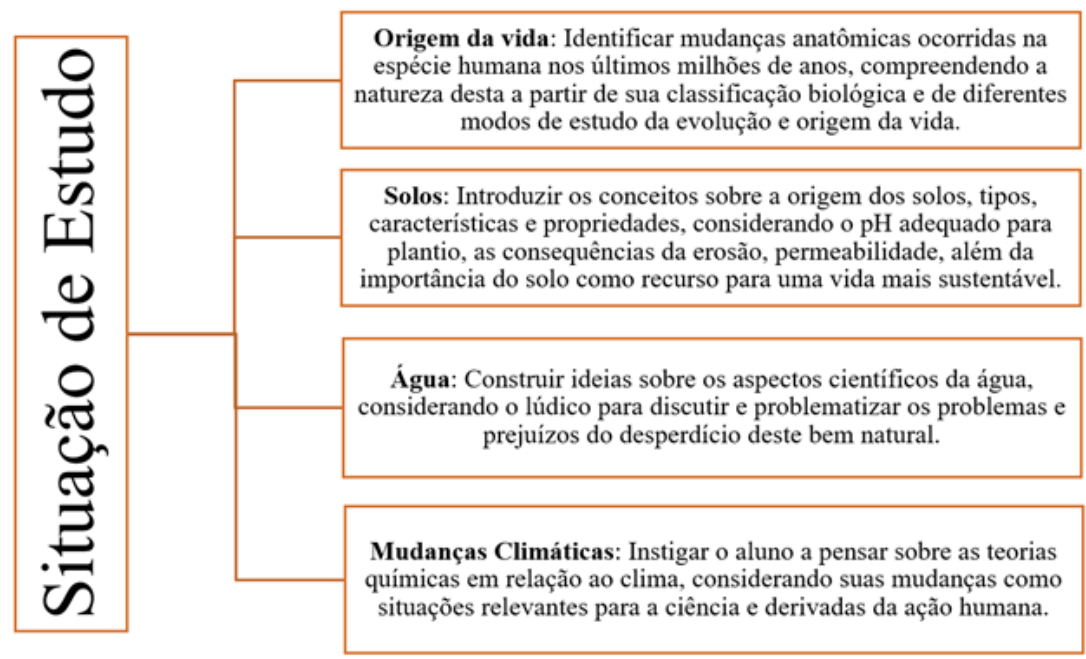

FONTE: Os autores (2017)

No término da aplicação das SE por dupla de professores, noutro momento das Rodas de Conversa, em meio ao diálogo sobre as certezas e incertezas de trabalhar com essa metodologia no ensino de ciências, em relação às suas especificidades e particularidades, instigou-se os professores a pensarem sobre a organização curricular de ciências na educação básica por meio da metodologia de SE, considerando o trabalho do professor a ser desenvolvido.

Nesse sentido, as passagens abaixo, exclamações de cada participante das Rodas de Conversa, transcritas em um diário de bordo pelo professor investigador, derivam não apenas do bate-papo no tempo/espaço de diálogo entre esses professores, mas da vivência e dos resultados da aplicação da SE desenvolvida por eles na escola; logo, entende-se que as concepções que esses professores apresentam sobre a possibilidade de organizar o trabalho docente à luz da SE deriva de aspectos concretos e práticos de atividades realizadas na realidade da aplicação da organização curricular, não apenas de um discurso respaldado ou de leituras que fundamentam essa prática.

Ainda, destaca-se que a amplitude da estratégia de coleta de ideias e concepções dos PFI na Roda de Conversa derivou-se da questão: "A SE pode ser utilizada no ensino de ciências/química como forma de ensinar/organização de trabalho? Por quê?"'. Este passo no trabalho é relevante para que se possa entender, como afirma Mannheim (1964, p. 151), que: 
la interpretación se ocupa de la más profunda comprensión del sentido. La explicación genético-causal proporciona la historia de las condiciones de la actualización y la realización del sentido. Sin embargo, el sentido mismo no puede ser, en última instancia, explicado causalmente. El sentido en su contenido más auténtico sólo puede ser compreendido o interpretado (apud MUÑOZ, 1993, p. 53).

Diante da questão, a PFI Tha expressou que a metodologia de Situação de Estudo "pode ser utilizada no ensino de ciências/química como forma de ensinar os alunos e organizar o trabalho docente por contextualizar um determinado conteúdo, motivando o estudante a interagir mais; ao se desvincular do método tradicional de ensino, o tema problematizado acaba por vincular mais a vivência dos educandos e qualificando os saberes docentes". A PFI Ca reflete que "organizar o trabalho pela SE é uma maneira de planejar. O professor que optar em trabalhar com SE vai contemplar os conteúdos de forma mais interdisciplinar e contextualizada, visando à realidade do aluno e facilitando a aprendizagem".

Nesta perspectiva, PFI Jé afirma que "é possível organizar o trabalho docente a partir da SE, pois é por meio dela que se configura a ação de educar por meio daquilo que os alunos sabem; a vivência deles faz parte da aprendizagem, pois é a partir dela que o professor deve facilitar o desenvolvimento do conteúdo científico". Para essa professora, inicialmente, apresenta-se o conteúdo/tema para os alunos e, na sequência, se propõe uma socialização de ideias para que se possa perceber quais são os saberes dos alunos e o que é interessante, para eles, aprender. Além disso, Jé reflete que "a aplicação da atividade por meio da SE perpassa por uma metodologia de fácil acesso ao estudante, o que facilita a interação destes com o conteúdo, com o colega e com a aprendizagem".

Ainda, na visão do PFI Bru, "a SE pode ser utilizada como mecanismo de organização do trabalho docente por trazer temáticas dentro dos conteúdos necessários da série em que está sendo desenvolvida; essas práticas auxiliam para que o aluno consiga uma melhor absorção do conteúdo". Não obstante, o PFI Fa reflete que "organizar o trabalho por meio da SE é vincular, além da aprendizagem do aluno, a qualificação e o aperfeiçoamento aos saberes docentes, pois o professor precisará buscar novas informações e relações com o contexto do aluno; deixa-se de ensinar e aprender de formas mecânica e monótona para facilitar a construção do conhecimento de forma conjunta".

Por fim, de acordo com a PFI Isa, "entende-se que a SE é uma forma de organizar o trabalho docente desde que o professor, munido de competências e habilidades, consiga vincular o conteúdo específico aos saberes cotidianos do aluno, pois a SE é rica em conceitos e precisa, pela ação dos envolvidos, 
na maximização dos processos de ensino e aprendizagem, relacionar o saber científico ao contexto sociocultural do aluno seja por meio do lúdico, do experimento ou da pesquisa".

Nessa perspectiva, analisando-se as manifestações dos diferentes PFI pode-se perceber que estes focam, com exclusividade os PFI Bru e Isa, fortemente no domínio do conteúdo a ser ensinado, mesmo vinculando-se a metodologia de SE. A PFI Tha também destaca a importância do domínio do conteúdo específico, contudo demonstra, assim como o PFI Fa, outros aspectos que estão relacionados à formação do professor, seja em metodologias ou saberes. Para Fiorentini et al. (2011), essa ligação exclusiva do professor à ideia de conteúdo também é importante, como comprovado em seus argumentos, quando apresenta esse aspecto e seus desdobramentos para a ação docente em sala de aula.

Este domínio profundo do conhecimento é fundamental para que o professor tenha autonomia intelectual para produzir o seu próprio currículo, constituindo-se efetivamente como mediador entre o conhecimento historicamente produzido e aquele - o escolar reelaborado e relevante socioculturalmente - a ser apropriado/construído pelos alunos. Este domínio e a reflexão epistemológica são fundamentais sobretudo nas áreas de ciências e matemática [...] (FIORENTINI et al., 2011, p. 316).

Logo, entende-se que, de acordo com as colocações dos professores, derivadas da vivência sobre as atividades realizadas na escola - aplicação de SE - parceira do projeto Rodas de Conversa, a SE pode ser utilizada como uma proposta de organização do trabalho docente por se configurar em uma metodologia que, além de priorizar um método de ensino pautado na abordagem contextualizada e interdisciplinar dos conteúdos, a seleção e a organização destes estão relacionadas a uma temática que faz parte do contexto sociocultural do estudante.

Neste sentido, por meio da análise hermenêutica sobre a fala dos PFI, pode-se perceber um fio condutor de ideias que abraçam o ato pedagógico, ainda em formação inicial, na educação básica à luz da SE como proposta de trabalho docente. Na Figura 3, apresenta-se o fio condutor da organização do trabalho docente por meio da SE na perspectiva destes professores. 
FIGURA 3 - ANÁLISE DAS ESCRITURAS DOS PFI SOBRE A ORGANIZAÇÃO DA PROPOSTA

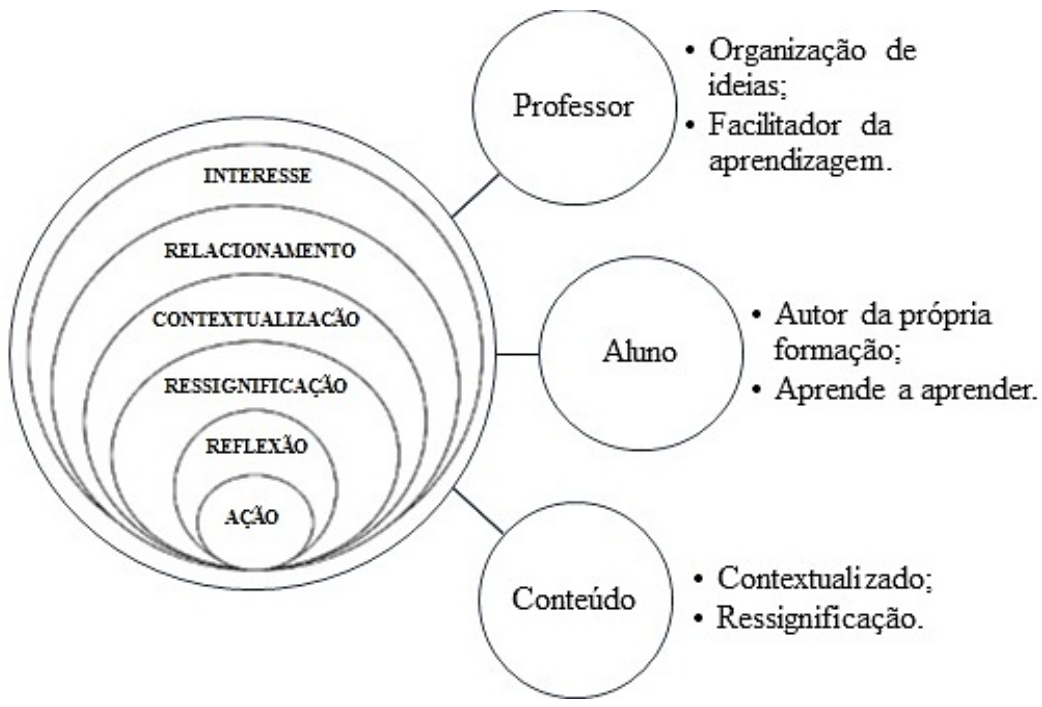

FONTE: Os autores (2017).

Observando-se a imagem acima, percebe-se que os PFI ajuízam a ideia central de organizar o trabalho docente por meio da SE por esta proporcionar, ao mesmo tempo, três vias diferentes. 1 - ao professor: a organização das ideias e fazê-lo agente facilitador da construção de conhecimento, minimizando a ideia de que o professor é ator principal dos processos de ensino e aprendizagem, além de ser o detentor do saber; 2 - ao aluno: ele aprende na prática a ação de aprender a aprender para se tornar autor da própria formação; o aluno passa a ser o principal constituinte de sua formação, aprendendo na medida em que se dedica e se interessa pela atividade e, por último, 3 - ao conteúdo: apresentado de uma forma diferenciada, a qual permeia as ações de contextualização e ressignificação dos saberes do senso comum sobre um viés científico; o conteúdo parte daquilo que o aluno sabe, de suas vivências e histórias de vida, sendo contextualizado e ressignificado à luz dos saberes científicos.

Essas colocações são visíveis ao interpretar o funil do conhecimento, o qual originaliza a tríade professor-aluno-conteúdo. Nele, é possível perceber que a primeira parte vinculada à organização do trabalho docente por meio da $\mathrm{SE}$ se encontra o interesse pela metodologia e a organização do tema. Em segundo plano, tem-se o relacionamento do tema com o conteúdo de ensino programado pelo professor a fim de que este possa contextualizar/relacionar esses saberes ao 
contexto sociocultural do aluno, como terceiro passo. Na sequência, percebe-se que o professor precisa ressignificar a aprendizagem do aluno; momento em que ele aplica o conhecimento adquirido em sua realidade, sendo reorganizado de forma satisfatória pela ação conjunta ao professor. No quinto passo cabe a reflexão do aluno em relação ao conhecimento construído sobre o seu contexto e, posteriormente, a ação de aplicá-lo para transformar sua realidade de forma consciente e ética.

Nessa conjuntura, percebe-se a partir da fala dos PFI e do fio condutor presente no funil do conhecimento, para além da formação inicial desses sujeitos, mas o real reconhecimento das responsabilidades das instituições de ensino superior, juntamente com seus docentes, quanto à formação inicial de professores de química competentes e habilidosos em desenvolver atividades que valorizam a aprendizagem científica do sujeito da educação básica, compreendendo suas necessidades diante do contexto atual, aliando a compreensão sobre a importância de metodologias e práticas pedagógicas que melhor norteiam os processos de ensino e aprendizagem. Afinal, essa ação faz com que esses sujeitos possam buscar uma formação continuada, após a graduação na universidade, pautada no aperfeiçoamento didático e na autorreflexão na/sobre a excelência de sua formação com qualidades organizativas, resolutivas e críticas.

\section{Considerações finais}

Diante do exposto neste trabalho, em comunhão aos dados obtidos por meio da investigação e interpretados pelo método fenomenológico da hermenêutica, percebe-se que os futuros professores da educação básica, participantes ativos desta pesquisa, compreendem a necessidade do processo de reconfiguração curricular organizado por meio da metodologia de Situação de Estudo, pois nas falas, tanto da montagem e organização da SE quanto de sua aplicação no ensino de ciências, percebe-se que os PFI passaram a avaliar constantemente a metodologia elaborada como minimização/resolução para os inúmeros problemas enfrentados nos processos de ensino e aprendizagem.

Nessa perspectiva, entende-se que o espaço de diálogo nas Rodas de Conversa sobre as diferentes metodologias que podem qualificar os processos educacionais e intensificar o trabalho docente realizado em sala de aula, permitindo uma reflexão entre as certezas e incertezas do ser professor, proporcionou saberes aos PFI para que pudessem pensar e refletir a partir do planejamento e da prática pedagógica à luz da SE, buscando reconstruí-la para melhorar os 
processos de contextualização e ressignificação de saberes científicos aos saberes da vivência dos alunos.

Essa ação de reconstruir uma SE após sua aplicabilidade é importante porque, por meio de análises durante as aulas, pode-se perceber se os estudantes mostraram ter ampliado suas compreensões sobre a temática ou não, tornando-se relevante reconhecer o papel da SE para aquele contexto, afinal a aprendizagem que ocorre por meio de uma SE, em alguns casos, pode até ser insuficiente e pouco estruturada, mas não pode ser descontextualizada da vivência do sujeito; logo, é necessário que o professor consiga se reinventar e reorganizar sua didática diante da sua realidade escolar/social.

Destarte, as contribuições da metodologia da SE no processo de reconstrução do currículo, reorganizando o trabalho docente, na percepção dos professores em formação inicial, podem ser sistematizadas, de modo geral, como: a organização das ideias sobre o conteúdo e a superação das práticas de ensino tradicionais, a necessidade real de buscar novos conhecimentos e o repensar da prática educativa, o papel ativo do aluno em sua formação e os saberes construídos e ressignificados por meio da contextualização. Esta postura, apresentada de forma implícita na fala dos PFI, dificilmente seria desenvolvida a partir de disciplinas de estágios em cursos de graduação ou pela ação individual do professor no campo do trabalho, após sua formação inicial.

\section{REFERÊNCIAS}

ABBAGNANO, N. Dicionário de Filosofia. São Paulo: Martins Fontes, 1998.

AZANHA, J. M. P. Uma reflexão sobre a formação do professor da escola básica. Educação e Pesquisa, São Paulo, v. 30, n. 2, p. 369-378, maio/ago. 2004

BEDIN, E.; DEL PINO, J. C. Concepções de professores sobre situação de estudo: rodas de conversa como práticas formadoras. Interfaces da Educ., Paranaíba, v. 8, n. 22, p. 154-185, 2017.

BRASIL. Ministério da Educação. Secretaria de Educação Média e Tecnológica. Parâmetros Curriculares Nacionais Ensino Médio. Bases Legais - Linguagens, Códigos e suas Tecnologias. Brasília: MEC/SEMTEC, 2000.

CYRINO, E. G.; TORALLES-PEREIRA, M. L. Trabalhando com estratégias de ensino-aprendizado por descoberta na área da saúde: a problematização e a aprendizagem baseada em problemas. Cadernos de Saúde Pública, Rio de Janeiro, v. 20, n. 3, p. 780-788, 2004. Disponível em: <www.scielo.br/pdf/csp/v20n3/15.pdf>. Acesso em: 18 maio 2017. 
FIORENTINI, D.; SOUZA JÚNIOR, A. J. de; MELO, G. F. A. de. Saberes docentes: um desafio para acadêmicos e práticos. In: GERALDI, C. M. G.; FIORENTINI, D.; PEREIRA, E. M. de A. (Org.). Cartografia do trabalho docente: professor(a)-pesquisador(a). 2. ed. Campinas: Mercado de Letras. 2011. p. 307- 335.

MALDANER, O. A. Situações de Estudo no Ensino Médio: nova compreensão de educação básica. In: NARDI, R. (Org.). A pesquisa em Ensino de Ciências no Brasil: alguns recortes. São Paulo: Escrituras, 2007a. p. 237-253.

MALDANER, O. A. Ar atmosférico: uma porção do mundo material sobre a qual se deve pensar. In: FRISON, M. D. (Org.). Programa de melhoria e expansão do ensino médio: curso de capacitação de professores da área de ciências da natureza, matemática e suas tecnologias. Ijuí-RS: Editora Unijuí, 2007b. p. 18-46.

MALDANER, O. A.; ZANON, L. B. SE: uma organização curricular que extrapola a formação disciplinar em ciências. Espaços da Escola, v. 1, n. 41, p. 45-60, Ijuí-RS: Editora Unijuí, jul./set. 2001.

MARCELO, C. Formação de professores para uma mudança educativa. Porto: Porto Editora, 1999.

MITRE, S. M. et al. Metodologias ativas de ensino-aprendizagem na formação profissional em saúde: debates atuais. Ciência \& Saúde Coletiva, Rio de Janeiro, v. 13, supl. 2, p. 2133-2144, 2008.

MUÑOZ, J. C. G. El retorno de la sociologia del conocimiento de Mannheim a una epistemologia de corte weberiano. REIS - Revista Española de Investigaciones Sociológicas, n. 62, p. 45-59, 1993.

NÓVOA, A. Os professores e sua formação. Lisboa: Nova Enciclopédia, 1992.

PARO, V. H. Educação como exercício do poder: crítica ao senso comum. 2. ed. São Paulo: Cortez, 2010.

PIMENTA, S. G. Saberes pedagógicos e atividade docente. São Paulo: Cortez, 2000.

SANTOS, L. L. C. P. Dilemas e perspectivas na relação entre ensino e pesquisa. In: ANDRÉ, M. (Org.). O papel da pesquisa na formação e na prática de professores. Campinas, SP: Papirus, 2001.

TREVISAN, A. L.; TOMAZETTI, E. M.; ROSSATTO, N. D. (Org.). Diferença, cultura e educação. Porto Alegre: Sulina, 2010.

TRIVIÑOS, A. N. Introdução à pesquisa em ciências sociais: a pesquisa qualitativa em educação. São Paulo: Atlas, 2013.

Texto recebido em 17 de junho de 2017. Texto aprovado em 25 de dezembro de 2017. 
